DOI: http://dx.doi.org/10.12957/demetra.2014.10350

\title{
Informação sobre a presença de alérgenos nos rótulos de alimentos: responsabilidade do estado na garantia dos direitos à saúde e à alimentação adequada da população com alergia alimentar
}

\section{Information on the presence of allergens on food labels: the state's duty to ensure that people with food allergy have the right to health and adequate food}

Maria Cecília Cury Chaddad'

' Faculdade de Direito. Direito Constitucional. Pontifícia Universidade Católica de São Paulo. São Paulo, SP, Brasil

Correspondência / Correspondence

Maria Cecilia Cury Chaddad

E-mail: cecilia.cury@uol.com.br

\section{Resumo}

A população com alergia alimentar, estimada em cerca de $8 \%$ das crianças e entre $3 \%$ e $5 \%$ dos adultos, necessita manter uma dieta que exclua a presença de alérgenos, como forma de garantir seu bem-estar e sua existência digna. Tendo em vista a inter-relação existente entre o direito à saúde e o direito à vida, assim como aquela existente entre o direito à saúde e o direito à alimentação adequada, há que se garantir a disponibilização de alimentação dieteticamente adequada, o que, no caso de quem tem alergia alimentar, demanda a garantia de alimentação livre de alérgenos. Assim, aponta-se a responsabilidade do Estado em proteger os direitos à saúde e à alimentação adequada desta parcela da população, que necessita de informações sobre a presença de alérgenos nos rótulos dos alimentos.

Palavras-chave: Direitos Fundamentais. Direitos Sociais. Direito à Saúde. Direito à Alimentação Adequada. Direito à Informação.

\section{Abstract}

People with food allergy, about $8 \%$ of children and $3 \%$ to $5 \%$ of adults, must keep a diet that excludes the presence of allergens, as a way to guarantee their well-being and a decent life. Given 
the interrelationship between the right to health and right to live, as well as the one between the right to health and the right to adequate food, the availability of dietetically adequate food has to be guaranteed. For those who have food allergy, this requires the guarantee of allergen-free food products. Thus, this paper discusses the State's duty to protect the rights to health and adequate food of such segment of the population, who needs information about the presence of food allergens on food labels.

Key words: Fundamental Rights. Social Rights. Right to Health. Right to Adequate Food. Right to Information.

\section{Introdução}

As pessoas que têm alergia alimentar demandam, em função de tal fato, atenção especial por parte do Estado, mormente no que se refere ao sistema de proteção à saúde. O fornecimento de alimentação adequada, com especial atenção às restrições alimentares, é um dever do Estado intrinsecamente relacionado à sua obrigação de promover o direito à saúde e à alimentação adequada. Nesse contexto, o Estado deve atentar para a promoção de medidas que viabilizem, ao consumidor com alergia alimentar, o direito de obter informações sobre a presença de alérgenos nos rótulos dos produtos.

Serão trazidos à baila os fundamentos normativos que justificam o dever de o Estado tutelar os direitos à saúde e à alimentação adequada da população com alergia alimentar, assim como alguns julgados da justiça comum e das cortes superiores que apontam como o Poder Judiciário tem enfrentado o tema do direito à saúde, à alimentação adequada e à informação.

\section{Dados sobre a alergia alimentar}

A fim de reforçar a relevância dos cuidados com a saúde e com a alimentação da população com alergia alimentar para o sistema jurídico, cumpre trazer à baila alguns dados estatísticos e técnicos que servem de fundamento para as premissas aqui adotadas.

A alergia alimentar é definida como uma hipersensibilidade do organismo a algo ingerido, inalado ou tocado, gerando uma resposta do sistema imunológico, que vê como ameaça uma dada substância, no caso, um alimento (ou mais). ${ }^{1}$ Em virtude de diversos fatores, como genética, 
hábitos de vida, consumo de alimentos ultraprocessados e excesso de higiene, o número de casos de alergia alimentar vem aumentando consideravelmente ao redor do mundo.

Apesar do notável aumento de casos, não há no Brasil, até o momento, dados nacionais sobre a prevalência da alergia alimentar, o que faz com que ainda não tenhamos informações precisas sobre o número de pessoas com alergia alimentar e quais são os alimentos que mais desencadeiam reações alérgicas na população brasileira.

Por tal motivo, os estudos nacionais acerca do tema se baseiam em pesquisas realizadas com outras populações, especialmente a população americana, na qual, de acordo com dados da Food Allergy Research \& Education, a alergia alimentar é um problema de saúde pública em crescimento, atingindo mais de 15 milhões de americanos, dos quais nove milhões seriam adultos (aproximadamente 4\% da população adulta) e seis milhões de crianças (cerca de 4\% das crianças, assim consideradas as pessoas até 18 anos de idade). ${ }^{2}$ Vale destacar, ainda, que a National Health Interview Survey indicou um aumento de $18 \%$ nos casos de alergia alimentar entre pessoas de até 18 anos, de 1997 a $2007 .^{3}$

Na Europa, dados apontam que aproximadamente 17 milhões de europeus sofrem de alguma alergia alimentar, dos quais 3,5 milhões seriam pessoas com menos de 25 anos, havendo indicação de que a alergia em crianças de 0 a 5 anos dobrou nos últimos dez anos, com aumento significativo de internações por reações severas como anafilaxia. ${ }^{4}$ No Canadá, o Health Canada, responsável por tutelar a saúde da população canadense, estima que a prevalência de alergia alimentar seja da ordem de $5-6 \%$ das crianças e $5-6 \%$ dos adultos. ${ }^{5}$

Em virtude da reconhecida relevância do número de pessoas que sofrem com alergia alimentar nos países mencionados, estes já aprovaram normas que cuidam da rotulagem destacada da presença dos alérgenos que mais afetam a população. No Brasil, onde essa população tende a seguir os mesmos percentuais, o déficit de pesquisa sobre o tema, a falta de regulamentação da obrigatoriedade de informação sobre a presença de alérgenos e a pouca divulgação da importância da dieta causam inegável prejuízo à saúde das pessoas com alergia alimentar.

A maioria das normas internacionais que cuidam da rotulagem de alérgenos em alimentos traz a obrigatoriedade de destaque da presença de oito alérgenos, que respondem por $90 \%$ dos casos de hipersensibilidade alimentar, a saber: leite, soja, ovo, oleaginosas, amendoim, peixe, crustáceos e cereais que contêm glúten.

Para uma melhor compreensão das consequências do consumo de substâncias alergênicas por quem tem alergia alimentar, vale trazer brevíssimas explicações sobre os mecanismos envolvidos nas reações alérgicas e as possíveis reações que podem advir da exposição ao alérgeno 
De acordo com a definição contida no documento elaborado pela Sociedade Brasileira de Pediatria em conjunto com a Associação Brasileira de Alergia e Imunopatologia, denominado "Consenso Brasileiro sobre Alergia Alimentar", de 2007, a ingestão de um alimento pode resultar em reações a depender da susceptibilidade individual de cada pessoa, podendo ser classificadas em: não imuno-mediadas (intolerância alimentar) ou imuno-mediadas (hipersensibilidade alimentar ou alergia alimentar). ${ }^{6}$

Tem-se, assim, que, nas reações não imuno-mediadas, típicas das intolerâncias alimentares, há uma deficiência enzimática que dificulta a absorção de um dado elemento (por exemplo, a lactase, que é a enzima que processa a lactose, nome do açúcar presente no leite de vaca). A seu turno, a alergia alimentar manifesta-se quando há uma resposta do sistema imune do organismo, seja decorrente da ação de imunoglobulinas (IgE mediados) ou não (não IgE mediados), com a consequente liberação de histamina.

No caso das reações mediadas por IgE, a sensibilização a alérgenos alimentares ocorre com a formação de anticorpos específicos da classe $\mathrm{IgE}$, levando à sensibilização imediata. Para esse grupo, as manifestações mais comuns, segundo o Consenso Brasileiro sobre Alergia Alimentar de 2007, são: "reações cutâneas (dermatite atópica, urticária, angioedema), gastrintestinais (edema e prurido de lábios, língua ou palato, vômitos e diarreia), respiratórias (asma, rinite) e reações sistêmicas (anafilaxia com hipotensão e choque). ${ }^{6}$

Há reações classificadas como mistas, que são mediadas por IgE e por células (linfócitos T e citocinas pró-inflamatórias), grupo em que estão aqueles que apresentam as seguintes manifestações clínicas: esofagite eosinofílica, gastrite eosinofílica, gastrenterite eosinofílica, dermatite atópica, asma e a hemossiderose, segundo referido Consenso.

O último grupo, pertencente à classe das manifestações não mediadas por IgE, é composto pelas pessoas que não apresentam reações alérgicas tão imediatas, podendo ocorrer horas ou dias após a ingestão de substância alérgena. Neste grupo, segundo o citado Consenso Brasileiro sobre Alergia Alimentar, estariam as seguintes manifestações clínicas: proctite, enteropatia induzida pela proteína alimentar e enterocolite induzida por proteína alimentar.

Assim, as respostas que o organismo tem ao ser exposto a uma substância alergênica variam de pessoa para pessoa. Há quem apresente reações imediatas e quem reaja apenas algumas horas ou até mesmo dias depois, lembrando que há casos em que as reações independem da efetiva ingestão do alimento, bastando o indivíduo sensibilizado tocar ou inalar dada substância alérgena.

Independentemente do mecanismo presente, segundo o Consenso Brasileiro sobre Alergia Alimentar, o tratamento da alergia alimentar depende da exclusão absoluta de alérgeno, sendo este o único tratamento preconizado até o momento para as alergias alimentares. 


\section{Direito à saúde}

Os direitos sociais, voltados à promoção da melhoria das condições de vida e da igualdade material das pessoas, abrangem tanto prestações positivas, relacionadas à saúde, à moradia, ao lazer, à educação e à alimentação, quanto os direitos de defesa, destacando-se direitos trabalhistas, como o de greve, ao recebimento de adicionais noturno e de periculosidade, e direitos previdenciários.

Se, de um lado, a vida é pressuposto para o exercício de todos os demais direitos; de outro, a tutela do direito à vida demanda a defesa do direito à saúde, implicando a necessidade de que o Estado atue na prevenção e no tratamento de males à saúde.

Lenir Santos esclarece que a tutela do direito à saúde demanda a consideração "das condições que cercam o indivíduo e a coletividade", até porque o direito à saúde não deve ser apreciado apenas sob a ótica individual; há que se tutelar também os aspectos de interesse difuso, coletivo e individual homogêneo. ${ }^{7}$ José Afonso da Silva entende que a saúde é direito de todos e dever do Estado, "que a deve garantir, mediante políticas sociais e econômicas que visem à redução do risco de doenças e outros agravos". ${ }^{8}$

Em virtude de sua inegável relevância, o direito à saúde encontra guarida tanto no contexto internacional, quanto no âmbito interno do ordenamento jurídico brasileiro. No âmbito internacional, a Declaração Universal dos Direitos Humanos atrela tal direito ao bem estar, dispondo no artigo XXV, item 1, que "toda pessoa tem direito a um padrão de vida capaz de assegurar a si e a sua família saúde e bem-estar". ${ }^{9}$

Ao seu turno, o Pacto Internacional dos Direitos Econômicos, Sociais e Culturais (PIDESC) prevê, em seu artigo 12, que "toda pessoa tem direito à saúde, entendida como o gozo do mais alto nível de bem-estar físico, mental e social”, sendo dever do Estado, nos termos da alínea c, atentar para "a prevenção e tratamento das doenças epidêmicas, endêmicas, profissionais e outras, bem como a luta contra essas doenças". ${ }^{10}$

Na esfera normativa interamericana, o tema vem tutelado no âmbito do Protocolo Adicional à Convenção Americana sobre Direitos Humanos em Matéria de Direitos Econômicos, Sociais e Culturais, concluído em 17 de novembro de 1988, ("Protocolo de São Salvador"). Esta prevê, no artigo 10, que a implementação do direito à saúde demanda, dentre outras medidas: (i) a prevenção e tratamento das doenças endêmicas; (ii) a educação da população sobre prevenção e tratamento dos problemas da saúde; e (iii) a satisfação das necessidades de saúde dos grupos de mais alto risco e que, por sua situação de pobreza, sejam mais vulneráveis. ${ }^{11}$

A Organização Mundial da Saúde ("OMS”), por sua vez, define que a saúde não se limita à ausência de doença, abrangendo também o completo bem-estar físico, mental e social. ${ }^{12}$ 
Nota-se, de todo o exposto, que a tutela do direito à saúde, que engloba o bem-estar físico, mental e, no âmbito interamericano, social, é obrigação assumida e reafirmada pelo Brasil no âmbito internacional. Por isso, o Estado brasileiro deve tomar todas as medidas que estiverem ao seu alcance para salvaguardar tal direito, o que implica o dever de tutelar a saúde das pessoas com alergia alimentar, que necessitam de cuidados especiais com sua dieta, a fim de evitar danos ao seu bem-estar.

No âmbito interno, o direito à saúde ganhou status constitucional peculiar a partir da Constituição Federal de 1988, que não se limitou a tratar do tema sob o prisma da repartição de competências legislativas (artigo 24, XII) e administrativas (artigo 23, II). ${ }^{13}$ Pelo contrário, o texto constitucional de 1988 previu o direito à saúde como um direito social (artigo 6º) e ainda trouxe uma série de regras e princípios próprios.

Com efeito, no plano constitucional, no título que trata da Ordem Social, foi incluído um capítulo dedicado especificamente ao direito à saúde (Título VIII, Seção II), no qual se estatui que, para esse direito ser garantido, é dever do Estado, nos termos do artigo 196, promover políticas sociais e econômicas com vistas a (i) reduzir risco de doença e de outros agravos e (ii) garantir o acesso universal e igualitário às ações e serviços para a promoção, proteção e recuperação da saúde.

Afirmar que todos têm direito à saúde, constitucionalmente garantido, significa dizer que a todos deve ser assegurada qualidade de vida. Isto é, ao Estado é dado o dever de afirmar o acesso universal e igualitário a ações e serviços de promoção, proteção e recuperação da saúde, objetivando evitar o risco de doenças ou seu agravamento.

Nesse ponto, vale destacar que o Supremo Tribunal Federal (STF) já entendeu reiteradas vezes que o direito à saúde é uma consequência constitucional indissociável do direito à vida, sendo relevante a garantia de sua tutela pelo Estado. ${ }^{14}$

Dúvida não há de que o direito à saúde está abrangido pelo rol de direitos fundamentais, não apenas pela questão topológica (o artigo 6⿳0 da Constituição Federal de 1988, que cuida do direito à saúde, está contido no título dos direitos e garantias fundamentais), mas, sobretudo, em vista do conteúdo que se revela de tal direito. Objetiva salvaguardar o bem-estar e a qualidade de vida, o que, em última análise, significa tutelar a existência digna de todos.

Ademais, ao tratar especificamente do direito à saúde, o constituinte objetivou, no artigo 197, cuidar dos serviços de saúde, e ainda das ações voltadas à promoção da saúde, ao prever que "são de relevância pública as ações e serviços de saúde" (grifos da transcrição). Assim, cabe ao Estado regular, fiscalizar e controlar as ações voltadas à garantia de tudo aquilo que se refere à saúde.

Se, de um lado, a tutela normativa do direito à saúde possui uma vertente positiva, relacionada ao direito a medidas do Estado com o fito de prevenir doenças e de tratá-las; de outro, há uma 
vertente negativa, implicando o direito de exigir do Estado e de terceiros que se abstenham de atos que possam causar mal à saúde de alguém.

Destaquem-se, outrossim, "as normas definidoras dos direitos e garantias fundamentais têm aplicação imediata”, nos termos do § 1ำ de seu artigo 5o da Constituição Federal de 1988, razão pela qual espera-se que o direito à saúde seja tutelado, quando analisado sob a perspectiva do tratamento, e implementado, se visto pela perspectiva da prevenção.

\section{Direito à alimentação adequada}

Há nítida correlação entre o direito à saúde e o direito à alimentação, sendo este o posicionamento do Comitê de Direitos Econômicos, Sociais e Culturais no Comentário Geral n 14, por meio do qual referido Comitê expressamente relaciona o direito à saúde ao direito à alimentação. ${ }^{15}$ Nesse sentido, Alessandra Gotti Bontempo destaca que "o direito à saúde abrange diversos fatores socioeconômicos que promovem as condições nas quais as pessoas podem desfrutar de uma vida (com) saúde, como a alimentação". ${ }^{16}$

No plano normativo brasileiro, vale mencionar a Lei n. 8.080, de 19 de setembro de 1990, a qual cuida das condições para a promoção, proteção e recuperação da saúde, "direito fundamental do ser humano", resultando no dever de o "Estado prover as condições indispensáveis ao seu pleno exercício". Nos termos do artigo $2^{\circ}$, a referida lei ainda prevê, em seu artigo $3^{\circ}$, que dentre os fatores determinantes da saúde está a alimentação. ${ }^{17}$

Neste ponto, há que se frisar que a alimentação adequada do indivíduo - que vai muito além da disponibilização de um prato de comida - é um relevante condicionante para a preservação de sua saúde e, consequentemente, para o desfrute do seu direito à vida.

No relatório apresentado pelo Brasil, em Roma, na Cúpula Mundial de Alimentação (CMA), ocorrida em 1996, consta a seguinte afirmação:

[...] o acesso à alimentação é um direito humano em si mesmo, na medida em que a alimentação constitui-se no próprio direito à vida. Negar esse direitoé, antes de mais nada, negar a primeira condição para a cidadania, que é a própria vida. ${ }^{18}$

A esse respeito, o médico Flavio Luiz Schieck Valente sustenta ser a alimentação adequada direito que condiciona o exercício do direito à vida, verbis: "sem uma alimentação adequada, tanto do ponto de vista de quantidade, como de qualidade, não há o direito à vida" ${ }^{19}$ 
Neste diapasão, Ana Elizabeth Lapa Wanderley Cavalcanti ressalta: "Verificamos que o direito à alimentação não é apenas o direito de 'matar' a fome, mas também o de se nutrir, ter segurança na alimentação e possibilitar a manutenção da vida e da saúde de forma digna”. ${ }^{20}$

Quando se pensa na tutela do direito à alimentação, devemos recorrer ao mesmo cabedal normativo já indicado no item acima. A Declaração Universal dos Direitos Humanos trata do direito à alimentação como algo inerente ao direito à saúde e bem-estar, ao prever, no artigo XXV, que "toda pessoa tem direito a um padrão de vida capaz de assegurar a si e a sua família saúde e bem estar, inclusive alimentação". 9

Ao seu turno, o Pacto Internacional dos Direitos Econômicos, Sociais e Culturais (PIDESC) prevê o direito à alimentação no artigo 11, prescrevendo que a alimentação é conditio sine qua non para que uma pessoa tenha nível de vida adequado, o que abrange o dever de os Estados-partes adotarem medidas para melhorar os métodos de produção, conservação e distribuição de gêneros alimentícios, dentre outras questões, pela plena utilização dos conhecimentos técnicos e científicos e pela difusão de princípios de educação nutricional, o que guarda estreita relação com a proposta aqui apresentada. ${ }^{10}$

No âmbito do Protocolo de São Salvador, o tema é tutelado no artigo 12, o qual estatui que "toda pessoa tem direito a nutrição adequada, que lhe assegure a possibilidade de gozar do mais alto nível de desenvolvimento físico, emocional e intelectual”."21

De acordo com o entendimento atual acerca do tema, presente no Comentário Geral no. 12 do Comitê de Direitos Econômicos, Sociais e Culturais da ONU, o direito à alimentação abrange três elementos: (i) disponibilidade; (ii) adequação; e (iii) acessibilidade..$^{22} \mathrm{~A}$ disponibilidade se relaciona à existência de quantidade suficiente de alimento para a população mundial de hoje e provisão para alimentar as gerações futuras.

A adequação está atrelada à observância das necessidades dietéticas de cada indivíduo, não apenas no referente aos nutrientes, mas também no que tange às necessidades culturais e outras específicas de cada cidadão, que, no caso dos que têm alergia alimentar, seria a garantia de alimentos livres de ingredientes alergênicos, observadas as peculiaridades de cada qual das pessoas.

Por fim, a acessibilidade se subdivide em duas categorias: (i) econômica, pela qual o custo para aquisição de alimentos não pode resultar na impossibilidade de realização de outros direitos, como moradia, saúde e educação; e (ii) física, que abarca a consideração das pessoas fisicamente vulneráveis, incluindo crianças, adolescentes, idosos, pessoas com dificuldades de locomoção e, ainda, pessoas com problemas médicos persistentes.

Neste ponto, vale explorar as diretrizes indicadas no comentário n. 12 feito pelo Comitê de Direitos Econômicos, Sociais e Culturais da ONU, em 1999, que versa especificamente sobre o 
direito à alimentação, relacionando-o com a dignidade humana, sendo indispensável, de acordo com o comentário em questão, para o exercício de outros direitos. ${ }^{22}$

De acordo com o que se depreende da leitura do comentário $n^{\circ} .12$, o que se busca é garantir o acesso à alimentação adequada, a qual seria mais do que um pacote de calorias, proteínas e outros nutrientes (item 6). É indispensável considerar-se não apenas a quantidade de alimento, mas sua qualidade, a fim de garantir as necessidades dietéticas de uma dada população (item 8), pelo que propugna a adoção de medidas que visem manter, adaptar e reforçar as diversidades dietéticas (item 9). O alimento disponibilizado deve, ainda, estar livre de substâncias adversas, inclusive daquelas decorrentes do manejo inapropriado durante a cadeia produtiva (item 10) e ser adequado às pessoas vulneráveis (item 13). Cabe aos Estados-parte tomarem as medidas necessárias para respeitar, proteger e implementar o direito à alimentação (item 15), sendo certo que a omissão em regular tal direito de forma efetiva é vista como violação à Declaração Universal dos Direitos Humanos (item 19).

Em consonância com o contexto internacional, com a promulgação da Emenda Constitucional $n^{\circ}$. 64, aprovada em 4 de fevereiro de 2010, a Constituição Federal de 1988 conferiu, ao direito à alimentação, o status de direito fundamental, incluindo-o no rol de direitos sociais previstos no artigo $6^{\mathbf{o}}$, sendo, deste modo, um direito a ser respeitado, protegido e implementado pelo Estado. ${ }^{23}$

No plano infraconstitucional, destaca-se a Política Nacional de Alimentação e Nutrição (PNAN), aprovada pelo Conselho Nacional de Saúde por meio da Portaria no 710, de 10 de junho de 1999, que objetivou reunir o conjunto das políticas de governo voltadas à compreensão do direito humano universal à alimentação e nutrição, tendo, entre seus objetivos, a prevenção e controle dos distúrbios nutricionais e das doenças associadas à alimentação e nutrição, inclusive no que se refere à proteção da saúde daqueles que dependem de cuidados em sua alimentação como forma de prevenir ou evitar evolução do quadro. ${ }^{24}$ Em 17 de novembro de 2011, foi aprovada a Portaria $n^{\circ}$. 2715, que revogou a Portaria $n^{\circ} 710$, prevendo uma nova Política Nacional de Alimentação e Nutrição (PNAN). ${ }^{25}$

Vale destacar, ainda, que em 15 de setembro de 2006, foi aprovada a Lei $\mathrm{n}^{\circ}$. 11.346, regulamentada pelo Decreto $n^{\circ}$. 7.272, de 25 de agosto de 2010, que criou o Sistema Nacional de Segurança Alimentar e Nutricional (SISAN), com vistas a assegurar o direito humano à alimentação adequada. Previa, em seu artigo 2ํㅡㄹ na mesma linha do que consta do comentário $n^{\circ}$. 12, efetuado pelo Comitê de Direitos Econômicos, Sociais e Culturais da ONU, que o direito à "alimentação adequada é direito fundamental do ser humano, inerente à dignidade da pessoa humana e indispensável à realização dos direitos consagrados na Constituição Federal”, cabendo ao Estado o dever de adotar as políticas e ações que se façam necessárias para promover e garantir a segurança alimentar e nutricional da população. ${ }^{26,27}$ 
Frisem-se importantes facetas do direito à alimentação adequada, previstas na legislação que criou o SISAN: a garantia da segurança alimentar e a consideração das necessidades específicas, que envolvem o acesso a alimentos de qualidade e em quantidade suficientes, devendo ser consideradas, dentre outras questões: a (i) "promoção da saúde, da nutrição e da alimentação da população, incluindo-se grupos populacionais específicos e populações em situação de vulnerabilidade social” (artigo 4ํㅜ inciso III); (ii) "a garantia da qualidade [...] tecnológica dos alimentos" (artigo 4º inciso IV); e ainda, (iii) a "produção de conhecimento e o acesso à informação", temas intimamente relacionados ao objeto deste artigo.

Do exposto, temos que a alimentação adequada é condição para a fruição de outros direitos de grande importância, como o direito à saúde, sendo certo que um alimento somente pode ser visto como adequado se ele atender às necessidades dietéticas especiais de uma dada parcela da população. Com efeito, a PNAN deve levar em conta as necessidades alimentares especiais, observadas as peculiaridades daqueles portadores de alteração metabólica ou fisiológica que cause mudanças relacionadas à utilização biológica de nutrientes ou a via de consumo alimentar (enteral ou parenteral), seja ela provisória ou permanente.

Neste cenário, temos que o direito à saúde da população com alergia alimentar caminha de braços dados com o direito à alimentação adequada. Ou seja, se a dieta da pessoa com alergia estiver correta do ponto de vista nutricional, com a devida exclusão dos alérgenos no alimento, a saúde fica salvaguardada; ao passo que, se a dieta não estiver adequada, a saúde é sensivelmente abalada (por vezes, de maneira imediata e severa).

Ora, tendo a dieta um papel crucial na vida (pensando em existência e também na qualidade), é dever do Estado zelar para que seja garantido o atendimento às necessidades dietéticas da população com alergia alimentar, com o correspondente fornecimento de opções seguras aos cidadãos que têm alergia alimentar, donde se extrai a necessidade de que haja norma impondo o dever de destaque de alérgenos nos rótulos dos alimentos.

\section{Responsabilidade do estado no tocante aos direitos sociais}

Para Flávia Piovesan, inspirada nas lições de Hannah Arendt, os direitos humanos não são um dado, mas um constructo histórico, sendo fruto de trabalho de edificação diuturno por parte da sociedade. ${ }^{28}$

Os direitos humanos, que podem ser definidos como reivindicações morais, surgem quando há espaço e contexto para tanto, confirmando sua historicidade na medida em que são fruto de processos de construção e reconstrução. Nesse sentido, é a lição de Norberto Bobbio na Introdução da obra $A$ Era dos Direitos. ${ }^{29}$ 
A concepção contemporânea de direitos humanos ganhou força após o fim da 2a Guerra Mundial, oportunidade em que a humanidade se viu obrigada a tutelar normativamente os direitos da pessoa humana, a fim de evitar a repetição das grandes violações aos direitos da pessoa ocorridas no período da guerra. Nesse cenário surgiram diversos instrumentos internacionais de proteção aos direitos da pessoa humana, destacando-se a Declaração Universal dos Direitos Humanos, de 1948; e, em 1966, o Pacto Internacional dos Direitos Civis e Políticos (PIDCP) e o Pacto Internacional dos Direitos Econômicos, Sociais e Culturais (PIDESC). ${ }^{10,30,31}$

Ainda que os direitos sociais não tenham usualmente o mesmo grau dos direitos civis e políticos (como regra, com eficácia plena, independendo de norma regulamentando seu exercício), tais normas, mesmo que de aplicação progressiva, são vinculantes. É dizer, são de aplicação obrigatória, ainda que haja necessidade de alguma regulamentação para que se viabilize seu exercício.

Destarte, diante de normas que versam sobre direitos sociais, cabe ao Estado adotar medidas efetivas e com objetivos bem definidos, a fim de concretizar tais direitos, o que se dá por meio do respeito, proteção e implementação.

A realização dos direitos sociais constitucionalmente previstos depende de uma série de ações estatais, incluindo produção normativa e adoção de políticas públicas - estas de acordo com Alessandra Gotti Bontempo são:

[0] conjunto complexo de normas e atos tendentes à realização dos fins públicos consagrados pela Carta de 1988 - suscetível de controle pelo Poder Púbico -, e que possui como elementos estruturais: o programa (dimensão material da política pública), a ação-coordenação (coordenação do Estado para o atingimento de resultados determinados), o processo (sequência de atos tendentes a um fim, sendo fundamental nesse ponto da participação popular). ${ }^{32}$

Uma característica relevante dos direitos sociais, já mencionada, é que são direitos cuja aplicação se dá de forma progressiva; isto é, o Estado é obrigado a tomar tantas medidas quantas forem necessárias para que, na prática, tais direitos sejam fruíveis por seus destinatários.

Se, de um lado, há a compreensão de que a implementação de tais direitos se dá de maneira gradual, eis que está limitada à capacidade de recurso disponível em um dado momento; de outro, veda-se o retrocesso social e a omissão do Estado.

No tangente aos impactos jurídicos da omissão do Estado em tutelar os direitos fundamentais, a doutrina tem sustentado que essa inação representaria violação ao sistema jurídico, na medida em que ofenderia o princípio que veda tanto as normas que extrapolam, quanto as que vão aquém daquilo que o constituinte almejou, porque a proporcionalidade em sentido estrito impede não apenas o excesso, mas também a insuficiência de normas. 
Enfrentando, especialmente no tema da omissão do Estado em matéria de saúde, Luis Roberto Barroso afirma que o Poder Público "não pode se mostrar indiferente ao problema da saúde da população, sob pena de incidir, ainda que por censurável omissão, em grave comportamento inconstitucional". 33

Destarte, o silêncio do Estado em exigir rótulos claros no que tange à presença de alérgenos viola o sistema jurídico.

\section{Responsabilidade do estado em tutelar os direitos à saúde e à alimentação}

Como mencionado, o direito à saúde é um direito social previsto no artigo $6^{0}$ da Constituição Federal de 1988, cuja tutela merece especial atenção por parte do Estado em vista da inegável relevância da vida de uma pessoa, cabendo-lhe, nos termos do artigo 196 da Constituição Federal de 1988, garantir "mediante políticas sociais e econômicas que visem à redução do risco de doença e de outros agravos e ao acesso universal e igualitário às ações e serviços para a sua promoção, proteção e recuperação". ${ }^{34}$

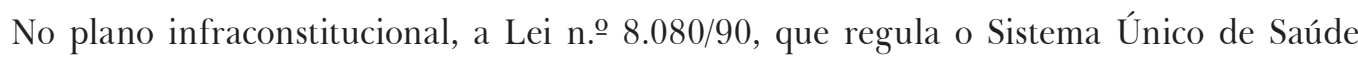
(SUS), preceitua ser a saúde "um direito fundamental do ser humano devendo o Estado prover as condições indispensáveis ao seu pleno exercício" (grifamos). ${ }^{17}$ Dentre os objetivos do SUS, de acordo com o inciso III do artigo $5^{\text {o }}$ da referida lei, está a "assistência às pessoas por intermédio de ações de promoção e recuperação da saúde com a realização integrada das ações assistenciais e das atividades preventivas".

Ademais, o artigo 7ำ da Lei em análise, esmiuçando aquilo que o artigo 198 da Constituição Federal de 1988 prevê, traz um rol de princípios que devem nortear as ações e serviços públicos de saúde que integram o SUS, destacando-se a necessidade de que haja "integralidade de assistência, entendida como um conjunto articulado e contínuo das ações e serviços preventivos e curativos, individuais e coletivos, exigidos para cada caso em todos os níveis de complexidade do sistema”.

Especificamente em relação a crianças e adolescentes, vale frisar que, nos termos do artigo 227 da Constituição Federal de 1988, o Estado deve assegurar a este grupo de pessoas, com prioridade absoluta, os direitos à vida, à saúde, à alimentação, dentre outros, devendo o Estado promover programas de assistência integral à saúde da criança, do adolescente e do jovem nos termos do parágrafo primeiro do dispositivo em comento. ${ }^{34}$

Ainda focando nas crianças, no plano infraconstitucional, a Lei $n^{\circ}$. 8.069/90 que dispõe sobre o Estatuto da Criança e do Adolescente (ECA), preconiza que "a criança e o adolescente têm direito à vida e à saúde, mediante efetivação de políticas sociais públicas que permitam o nascimento e o desenvolvimento sadio e harmonioso, em condições dignas de existência". ${ }^{35}$ 
Em vista da relevância dos direitos à saúde e à alimentação adequada e da imprescindibilidade de que aqueles que padecem de alergia alimentar tenham acesso à alimentação livre dos ingredientes que lhe causam reaçóes alérgicas, resta claro ser dever de o Estado, em todas as esferas, por se tratar de competência comum da União, dos estados, do Distrito Federal e dos municípios (artigo 23, inciso II, da Constituição Federal de 1988), prover todas as ações no sentido de prevenção dos agravos à saúde, o que passa necessariamente pelo fornecimento de alimentação adequada, com opções seguras para aqueles que têm alergia alimentar.

Sendo a garantia dos direitos à saúde e à alimentação adequada da população com alergia alimentar dependente direta do acesso à informação sobre a presença de alérgenos, é dever do Estado, na qualidade de responsável pela implementação de ações voltadas à garantia dos direitos sociais constitucionalmente previstos, promover as medidas cabíveis no sentido de garantir o efetivo exercício do direito à informação previsto no Código de Defesa do Consumidor (CDC), aprovado por meio da Lei Federal n'. 8.078/90. ${ }^{36}$

\section{Dever de garantir o direito à informação sobre a presença de alérgenos}

Partindo da premissa de que o direito à informação não é tutelado apenas com vistas a proteger (e capacitar) o cidadão contra o Estado, mas também para permitir o exercício da cidadania plena, temos que o direito à informação tem sua matriz no inciso XIV do artigo 5o da Constituição Federal de 1988.

Sob este prisma, Alexandre David Malfatti sustenta que o direito constitucional à informação, no que se refere às relações de consumo, tem três consequências: (i) o direito que o fornecedor tem de informar aos consumidores sobre os produtos e/ou serviços que pretende comercializar; (ii) o dever de o fornecedor informar aos consumidores sobre as características dos produtos e/ou serviços; e (iii) o direito de o consumidor ser informado. ${ }^{37}$

Para ele, "a Constituição Federal de 1988 impôs aos particulares o dever de informar, quando suas atividades - empresariais ou não - envolverem direta ou indiretamente a dignidade da pessoa humana ou outros direitos fundamentais", resultando no dever de observância da responsabilidade social. ${ }^{37}$ Nesta linha, Flávia Piovesan pontua que a agenda de direitos humanos também deve nortear a atuação do setor privado, destacando a necessidade das empresas terem responsabilidade social, cabendo ao Estado fiscalizar a observância, pelas empresas privadas, dos direitos sociais. ${ }^{38}$

É a partir desta vertente do direito à informação, que o considera como oponível à ordem econômica, em vista da necessidade de que o setor privado guie suas atividades pautado em sua responsabilidade social no dever de observância dos direitos fundamentais, que se sustentará o 
dever de destaque da presença de alérgenos nos produtos disponibilizados ao consumo. A este respeito, Sueli Alves da Costa destaca que

[...] a responsabilidade social apresenta-se como um conjunto de outras responsabilidades que têm alguns pontos em comum: são oriundas de movimentos sociais, de divulgação e convencimento ou imposição de padrões éticos alternativos e delineados em reação a uma crise de valores. ${ }^{39}$

Ainda sobre responsabilidade social, Maria da Conceição Maranhão Pfeiffer defende que as empresas privadas devem cumprir sua função social, o que abrange o dever de informação aos consumidores. ${ }^{40}$

Especificamente no plano infraconstitucional, o CDC estabelece normas de proteção e defesa do consumidor, de ordem pública e interesse social e, nas palavras de Claudia Lima Marques, "de uma visão liberal e individualista do Direito Civil”, passa-se "a uma visão social, que valoriza a função do direito como ativo garante do equilíbrio, como protetor da confiança e das legítimas expectativas nas relações de consumo no mercado". ${ }^{41}$

O CDC estatui a política nacional das relações de consumo, a qual tem "por objetivo o atendimento das necessidades dos consumidores, o respeito à sua dignidade, saúde e segurança, a proteção de seus interesses econômicos, a melhoria da sua qualidade de vida, bem como a transparência e harmonia das relações de consumo". ${ }^{36}$

Só se pode pensar em efetiva tutela do direito do consumidor quando há o respeito à dignidade, saúde e segurança do consumidor por parte dos atores das relações de consumo. Frise-se, inclusive, que com vistas a atingir este objetivo, o CDC indicou expressamente o dever de serem tomadas medidas governamentais "no sentido de proteger efetivamente o consumidor", inclusive no referente à garantia de padrões adequados de qualidade e segurança, características que guardam relação mais estreita com o objeto do presente trabalho (alínea "d" do inciso II do artigo $4^{\text {o }}$ do CDC). ${ }^{36}$

De acordo com o estabelecido no inciso V do artigo $4^{\circ}$ do CDC, um dos princípios da política nacional das relações de consumo é o "incentivo à criação pelos fornecedores de meios eficientes de controle de qualidade e segurança de produtos e serviços" ${ }^{36}$ Ademais, vemos que se trata de direito básico do consumidor, "a informação adequada e clara sobre os diferentes produtos e serviços, com especificação correta de quantidade, características, composição, qualidade e preço, bem como sobre os riscos que apresentem" (inciso III do artigo $6^{\mathbf{0}}$, destaques da transcrição). ${ }^{36}$

Ao seu turno, o artigo 31 do CDC, quando trata das condições para oferta e apresentação de produtos ou serviços, estatui que devem ser asseguradas as "informações corretas, claras, precisas, ostensivas e em língua portuguesa sobre suas características, qualidades, quantidade, composição, 
preço, garantia, prazos de validade e origem, entre outros dados, bem como sobre os riscos que apresentam a saúde e segurança dos consumidores" (grifo nosso). ${ }^{36}$

Especificamente no que se refere aos produtos para consumo (como alimentos, medicamentos, produtos de higiene e beleza), há que se destacar que, por controle de qualidade, deve-se compreender a capacidade de o fornecedor identificar, sem qualquer omissão ou falha, todos os componentes de um dado produto, ainda que o percentual de um elemento seja baixo. Isso se torna especialmente relevante no caso das pessoas com hipersensibilidade alimentar, pois o desencadeamento de uma reação alérgica muitas vezes independe da quantidade de exposição ao alérgeno, bastando que ele esteja presente, ainda que na forma de pequenas quantidades de alérgenos involuntariamente adicionado ao produto na linha de produção (os "traços").

Não é por outra razão que se sustentará, aqui, a necessidade de controle, não apenas dos ingredientes de um dado produto, mas também dos traços advindos do processo de produção, transporte ou armazenamento dos produtos, resguardando-se assim o pleno direito à informação dos consumidores.

A proposta de haver regulamentação da rotulagem de alérgenos e da obrigatoriedade de controle no manejo de substâncias alergênicas objetiva tutelar os direitos difusos de todos aqueles com alergia alimentar e que precisam garantir uma dieta livre dos alérgenos para terem sua saúde preservada.

Exatamente por conta da necessidade de se assegurar a proteção da saúde deste grupo de pessoas (e de seus cuidadores, em sentido amplo, abrangendo não apenas a família, mas os profissionais de saúde envolvidos no tratamento e acompanhamento da evolução da alergia alimentar), defende-se a necessidade de se garantir uma alimentação adequada aos indivíduos com hipersensibilidade alimentar, o que se daria por meio da correta rotulagem dos alérgenos nos produtos alimentícios, assim como a disponibilização de tais informações junto aos canais de atendimento aos consumidores, seja sítio eletrônico ou serviço telefônico de atendimento ao cliente.

Sendo a proteção à saúde um dos direitos básicos dos consumidores, devem ser tomadas todas as medidas necessárias para que se garanta a fruição de tal direito, o que, no caso da população alérgica, demanda a disponibilização de informações quanto à presença de alérgenos. Frederico da Costa Carvalho Neto pontua que "a informação é sem dúvida senão o mais importante, um dos mais importantes direitos dos consumidores". ${ }^{42}$ Nesta mesma linha, Cláudia Lima Marques é incisiva ao afirmar que o dever de informar representa "verdadeiro dever essencial, dever básico (art. 6º , inciso III) para a harmonia e transparência das relações de consumo", sendo "verdadeiro ônus atribuído aos fornecedores" ${ }^{43} \mathrm{O}$ dever de informar de maneira adequada e clara justificase pelo fato de que somente o fornecedor detém informações acerca dos itens que compõem um dado produto, visto ser ele quem o manipula, estando o consumidor, assim, em situação de 
vulnerabilidade, o que é ainda mais delicado quando se levam em conta os riscos que uma exposição a alérgenos pode causar na saúde de uma pessoa.

Enfrentando especificamente o dever de informar a composição, Alexandre Malfatti afirma que esse direito decorre da possibilidade de o consumidor possuir "características próprias - de saúde, credo, religião, etc. - que sejam incompatíveis com o produto ou serviço ofertado". ${ }^{37}$ Esta é a premissa aqui assumida: há uma parcela da população que necessita, para fins de tutela de seu direito à saúde, de informações precisas acerca do conteúdo dos produtos alimentícios.

É sabido que o consumidor fica à mercê daquilo que é mencionado no rótulo do produto, em inquestionável situação de vulnerabilidade (artigo 4º , inciso I, do CDC), não lhe sendo possível imaginar que aquilo que o rótulo indica não representa a totalidade da composição do produto. Isso, no caso das pessoas com alergia, como já mencionado, pode resultar em sérios danos à saúde do consumidor, sendo certo que, no caso de pessoas com alergia alimentar, as informações são especialmente relevantes na fase pré-contratual, relacionada com a leitura das informações contidas nos rótulos. Fátima Nancy Andrighi, a esse respeito, pontua:

[...] as informações prestadas na fase pré-contratual são essenciais para a formação da própria convicção do consumidor, pois somente a partir da plena ciência da quantidade, qualidade e riscos do serviço oferecidoé que o consumidor estará apto a decidir se deseja firmar o negócio. ${ }^{44}$

Somente os fornecedores têm condições de minimizar o que Roberto Augusto Castellanos Pfeiffer denomina de "a assimetria de informações", consolidando e transmitindo dados precisos acerca da presença de alérgenos no produto, sejam aqueles voluntariamente adicionados, ou aqueles advindos do processo de produção involuntariamente. ${ }^{45}$ Neste sentido, a busca pela correta identificação (e indicação) de todos os componentes de um dado produto guarda estreita relação com a preocupação do CDC (e da política nacional das relações de consumo) com a segurança do consumidor, o que, no caso dos alérgicos, é patente.

Também enfrentando a questão da vulnerabilidade informacional, Claudia Lima Marques pontua ser este "o maior fator de desequilíbrio da relação vis-à-vis os fornecedores, os quais, mais do que experts, são os únicos verdadeiramente detentores da informação". ${ }^{6}$

É justamente por conta da vulnerabilidade informativa dos consumidores, que se espera que os fornecedores atuem sempre lastreados pelo princípio da boa-fé objetiva, que resulta no dever de o fornecedor ceder todas as informações do produto ou serviço como forma de se conferir equilíbrio à relação de consumo. Ana Elizabeth Lapa Wanderley Cavalcanti afirma que "o dever de informar pode ser entendido como uma norma de comportamento que demonstra a boa-fé necessária para o equilíbrio da relação de consumo". ${ }^{20}$ 
O princípio da boa-fé objetiva ganha importante realce quando consideramos a necessidade que têm aquelas pessoas com alergia alimentar de obter informações precisas acerca do conteúdo dos produtos disponibilizados no mercado. É sabido que o CDC, como regra, veda a comercialização de produtos ou serviços que possam propiciar danos ao consumidor, tema ao qual são dedicados os artigos $8^{\circ}$ e 9o do CDC, que cuidam das regras aplicáveis aos produtos e serviços potencialmente nocivos ou perigosos. ${ }^{36}$

De acordo com tais normas, todos os produtos e serviços disponibilizados ao consumo devem conter informações necessárias e adequadas a seu respeito, sendo certo que, na hipótese de algum produto ou serviço, por natureza e fruição, acarretar riscos à saúde ou segurança do consumidor, ainda que considerados normais e previsíveis, além das informações genéricas a respeito dos ingredientes e funcionalidade, devem ser destacados ostensiva e adequadamente quais os riscos envolvidos, a fim de que os consumidores possam se proteger deles.

Importa destacar, ainda, que nos termos do artigo 10, veda-se o comércio de produto ou serviço cujo fornecedor saiba ou deva saber apresentar alto grau de nocividade ou periculosidade à saúde ou segurança. Assim, quando por natureza ou fruição houver algum risco de comprometimento da saúde ou da segurança, o fornecedor deve disponibilizar tal informação de maneira ostensiva e adequada.

O Decreto nº 2.181, de 20 de março de 1997, que dispõe sobre a organização do Sistema Nacional de Defesa do Consumidor, estabelece ser prática infrativa disponibilizar, no mercado de consumo, produto ou serviço "que acarrete riscos à saúde ou à segurança dos consumidores e sem informações ostensivas e adequadas" (art. 12, IX, “b”). Ademais, no mesmo Decreto, prevê-se como prática infrativa a oferta de produtos ou serviços "sem as informações corretas, claras, precisa e ostensivas, em língua portuguesa, sobre suas características, qualidade, quantidade, composição, preço, condições de pagamento, juros, encargos, garantia, prazos de validade e origem, entre outros dados relevantes" (art. 13, I). ${ }^{47}$

No caso de produtos contendo substâncias alérgenas, ainda que não sejam potencialmente nocivos ou perigosos a todos os consumidores, o contato com tais substancias expõem as pessoas com alergia alimentar a uma série de riscos, sendo certo que a prevenção dependeria unicamente da correta rotulagem dos produtos alimentícios. Assim, a fim de se atender ao disposto no artigo $9^{\circ}$ do CDC, sustenta-se o dever de o fornecedor "informar, de maneira ostensiva e adequada, a respeito da sua nocividade ou periculosidade". ${ }^{36}$ Frise-se que a eventual indicação da presença ou ausência de alérgeno deve ser precisa, sob pena de responsabilização pela disparidade de informações indicadas no produto, nos termos do artigo 18 do CDC. 
Abordando o que denomina de "vício de informação", Alexandre David Malfatti é bastante incisivo no sentido do dever de responsabilização do fornecedor no caso de imprecisão de informação. Eis que, para ele, se há defeito de informação, a falta de segurança decorre de legítima expectativa do consumidor frustrada pela ausência de informação precisa por parte do fornecedor sobre uso do produto ou fruição do serviço ou acerca dos riscos envolvidos. ${ }^{37}$

Neste toar, vale trazer à baila a lição de Antônio Herman V. Benjamim, para quem a ausência ou deficiência de informação resulta em vício de qualidade por insegurança ${ }^{48} \mathrm{Assim}$, muito embora um produto alimentício disponibilizado para consumo não seja, a priori, um produto nocivo ou perigoso para a saúde, a escassez de informação transforma-o numa ameaça para aquela parcela da população que possui restrições ao consumo de alguns ingredientes, podendo desencadear, ao consumir, reações alérgicas.

Especificamente no que se refere aos produtos alimentícios, Luciano Custódio Teixeira afirma que, em virtude da importância que os alimentos representam para a humanidade, seria razoável a configuração da responsabilidade objetiva no caso de danos relacionados à imprecisão de informações. ${ }^{49}$

O Tribunal de Justiça do Estado de São Paulo, analisando processo em que se pleiteava a indenização por danos morais por conta do consumo de palito picante que continha trigo, decidiu que a embalagem deveria conter informações claras sobre o conteúdo. Determinou o dever de indenizar, no caso, porque não havia informação específica no rótulo do produto quanto à presença de farinha de trigo na sua composição. No caso exposto, a reação do consumidor se deu após o consumo do produto, o qual não continha nenhuma referência quanto à presença do trigo na lista de ingredientes, impossibilitando o consumidor de saber que o consumo daquele produto causara danos à sua saúde..$^{50}$

No mesmo sentido foi a decisão do Tribunal Regional da $3^{a}$ Região, que sustentando ser razoável a suspensão de comercialização de produto que não indica a presença de óleo de soja, reforçou a tese de que as embalagens devem contemplar informações relativas à composição do produto. ${ }^{51}$

Se a defesa do consumidor é um direito constitucionalmente garantido e se o acesso a informações sobre a composição é o instrumento para controle de saúde pública, é razoável sustentar a necessidade de que os fornecedores apresentem informações relativas à presença de alérgenos, ainda que na forma de traços, pois até mesmo quantidades pequenas de alérgenos podem desencadear reações na população alérgica.

Vale destacar, ainda, decisão do Tribunal de Justiça do Rio Grande do Sul em um caso de reação alérgica advinda de consumo de produto que não continha alérgeno (leite) dentre seus ingredientes, mas que, por haver compartilhamento de maquinário, possuía traços de leite. Neste 
caso, confirmando decisão exarada pelo juízo de Porto Alegre, o tribunal em questão entendeu que a responsabilidade do fabricante do produto seria objetiva, pelo que somente poderia ser afastada se provasse não ter inserido o produto no mercado, que o defeito não existia ou que o evento danoso fosse oriundo de culpa exclusiva do consumidor, situações que não seriam aplicáveis no caso em comento.

Fundamentando-se no direito à informação do consumidor, decidiu-se que, ainda que na época da aquisição do produto não existisse nenhuma regulamentação específica da ANVISA acerca da necessidade de alertar da existência de produtos alergênicos, teria havido infração ao CDC pela falta de indicação de informações de forma precisa, quanto ao conteúdo do produto comercializado. Pela decisão em tela, resta claro que a ausência de informação destacada acerca da presença de alérgenos (independentemente da quantidade) é hipótese de responsabilidade objetiva, eis que a legislação que ampara dos direitos dos consumidores reitera ao longo de toda a norma que o consumidor tem direito à informação clara e precisa e que o fornecedor tem o dever de informar. ${ }^{52}$

Há que se destacar que, no caso de eventual dano à saúde de alguma pessoa com alergia alimentar, que ingeriu substância alérgena não indicada expressamente na embalagem do produto, não haveria espaço para eventual defesa da indústria alimentícia baseada no risco de desenvolvimento. Atualmente, ainda que o tema não seja regulado no Brasil, as indústrias já possuem pleno conhecimento da existência de um percentual considerável de pessoas com alergia alimentar e, assim, são passiveis de responsabilização no caso de acidente de consumo advindo de omissão de informações quanto à presença de alérgenos.

Pelo exposto, temos que a salvaguarda do direito a precisas informações quanto à presença de alérgeno é medida indispensável para a tutela dos direitos da população alérgica, a fim de que tenham assegurados seus direitos fundamentais à saúde e à alimentação adequada, previstos nos tratados internacionais e no texto constitucional brasileiro, especialmente na Declaração Universal de Direitos Humanos e no Pacto Internacional de Direitos Econômicos, Sociais e Culturais.

A título ilustrativo, vale pontuar que se percebe haver um processo evolutivo na legislação de diversos países quanto à obrigatoriedade de expressa indicação da presença de alérgenos nos rótulos de produtos alimentícios. Na Europa, Estados Unidos, Austrália e Nova Zelândia, o assunto vem sendo debatido há mais de uma década, sendo constantemente revisitado a fim de manter a atualização necessária ao atendimento das demandas da população alérgica e aos avanços das ciências. Em tais nações, sempre que um produto contiver algum ingrediente alérgeno incluído na em sua composição, tal fato deve ser destacado na embalagem, seja com negrito, informação entre parênteses ou lista apartada ao final da lista de ingredientes de modo que o consumidor possa facilmente identificar se o ingrediente que lhe causa reação alérgica está presente no produto. 


\section{Conclusões}

Apesar de ser assunto tratado na ordem internacional há mais de uma década, esta realidade não foi transplantada para a seara normativa brasileira até o momento, prejudicando muito as pessoas com alergia alimentar, seus cuidadores e profissionais de saúde, que ficam sem saber quais alimentos seriam seguros para esta parcela da população.

O percentual de pessoas com alergia alimentar é bastante expressivo, e o percentual de interessados na regulamentação da rotulagem se multiplica sensivelmente quando consideramos o número de cuidadores de uma criança alérgica que precisa de informações precisas para alimentá-la.

Laura E. Derr alerta que, para cada um alérgico, há cerca de dez pessoas não alérgicas envolvidas na compra de alimentos, o que reforça a tese da importância da correta rotulagem. ${ }^{53}$

Atenta a reivindicações da população, a ANVISA decidiu abrir os olhos para o tema da rotulagem de alérgenos em alimentos embalados. Em 29 de maio de 2014, a Diretoria Colegiada da agência decidiu abrir processo de consulta pública de proposta de regulamentação do assunto no Brasil para que, pelo prazo de 60 dias a contar de 16 de junho de 2014, os interessados possam apresentar manifestações acerca do tema. ${ }^{54} \mathrm{Em}$ menos de três dias de consulta aberta, já havia mais de 700 comentários, sendo a maciça parte advinda de familiares de crianças com alergia alimentar que se mostrava favorável à norma proposta, na medida em que a saúde de seus filhos e filhas estaria mais bem amparada com a aprovação de norma que cuidasse da obrigatoriedade da rotulagem de alérgenos. ${ }^{55}$

A aprovação de norma que imponha o dever de destaque da presença de alergênicos certamente beneficiará a população com alergia alimentar, hoje exposta ao risco de acidente de consumo pela dificuldade de identificar a presença de ingredientes alergênicos nos produtos.

\section{Referências}

1. Instituto Girassol. Grupo de Apoio aos Portadores de Necessidades Nutricionais Especiais. Guia prático para o diagnóstico e tratamento das alergias alimentares. São Paulo: Instituto Girassol. Grupo de Apoio aos Portadores de Necessidades Nutricionais Especiais; 2006.

2. Food Allergy Research \& Education. Food allergy facts and statistics for the U.S [Internet]. [acesso em 18 abr. 2014]. Disponível em: http://www.foodallergy.org/document.doc?id=194

3. Branum AM, Lukacs SL. Food allergy among U.S. children: trends in prevalence and hospitalizations. NCHS Data Brief. 2008; (10): 1-8.

4. European Food Information Council. Annual report 2012. Brussels: EUFIC; 2013. 39 p. 
5. Health Canada. Food allergies and intolerances [Internet]. 22 ago. 2012. [acesso em 10 abr. 2014]. Disponível em: http://www.hc-sc.gc.ca/fn-an/securit/allerg/index-eng.php

6. Suplemento do consenso brasileiro sobre alergia alimentar: 2007. Revista Médica de Minas Gerais [Internet]. 2008. 18 (1-S1). [acesso em 01/02/14]. Disponível em: http://www.sbp.com.br/pdfs/ Suplemento_18_1_S1_consenso_alimentar.pdf

7. Santos L. Direito à saúde e qualidade de vida. In: Santos L, organizador. Direito da saúde no Brasil. Campinas: Saberes; 2010.

8. Silva JA. Curso de direito constitucional positivo. $27^{\mathrm{a}}$ ed. São Paulo: Malheiros; 2006.

9. Assembléia Geral das Nações Unidas. Declaração Universal Dos Direitos Humanos. 10 dez. 1948. [Internet]. [acesso em: 02 jan. 2013]. Disponível em: http://portal.mj.gov.br/sedh/ct/legis_intern/ ddh_bib_inter_universal.htm

10. Brasil. Decreto no 591, de 6 de julho de 1992. Pacto internacional sobre direitos econômicos, sociais e culturais. [Internet]. [acesso em 03 jan. 2013]. Disponível em: http://portal.mj.gov.br/sedh/ct/ legis_intern/pacto_dir_economicos.htm

11. Brasil. Decreto n0 3.321, de 30 de dezembro de 1999. Promulga o Protocolo Adicional à Convenção Americana sobre Direitos Humanos em Matéria de Direitos Econômicos, Sociais e Culturais "Protocolo de São Salvador", concluído em 17 de novembro de 1988, em São Salvador. Diário Oficial da União, 31 dez. 1999.

12. World Health Organization. WHO definition of health. [Internet]. [acesso em 06 mar. 2013]. Disponível em: http://www.who.int/about/definition/en/print.html

13. Brasil. Constituição 1988. [Internet]. [acesso em 04 jan. 2014]. Disponível em: http://www.planalto. gov.br/ccivil_03/constituicao/constituicao.htm

14. 14 Brasil. Supremo Tribunal Federal. RE 271286-AgR, rel. Min. Celso de Mello, j. 12/09/00, DJ 24/11/00.

15. United Nations Committee on Economic, Social and Cultural Rights, General Comment General Comment 14. The right to the highest attainable standard of health: article 12 of the International Covenant on Economic, Social and Cultural Rights. UN Doc. E/C.12/2000/4, paragraph 21. Disponível em: http://daccess-dds-ny.un.org/doc/UNDOC/GEN/G00/439/34/PDF/G0043934. pdf?OpenElement.

16. Bontempo AG. A eficácia e acionabilidade dos direitos sociais: uma análise à luz da Constituição de 1988 [dissertação]. São Paulo: Pontifícia Universidade Católica de São Paulo; 2003.

17. Brasil. Lei no 8.080 , de 19 de setembro de 1990. Dispõe sobre as condições para a promoção, proteção e recuperação da saúde, a organização e o funcionamento dos serviços correspondentes e dá outras providências. Diário Oficial da União 20 set. 1990. [acesso em 01 fev. 2014]. Disponível em: http:// www.planalto.gov.br/ccivil_03/leis/18080.htm

18. Food and Agriculture Organization of the United Nations. Rome Declaration on World Food Security. World Food Summit; 13-17 nov. 1996; Roma, Italia [Internet]. [acesso em 08 mar. 2013]. Disponível em: http://www.fao.org/docrep/003/w3613e/w3613e00.htm 
19. Valente FLS. Do combate à fome, à segurança alimentar e nutricional: o direito à alimentação adequada. In: Valente FLS. Direito humano à alimentação: desafios e conquistas. São Paulo: Cortez; 2002.

20. Cavalcanti AELW. O impacto da rotulagem dos alimentos transgênicos no direito da personalidade e na sadia qualidade de vida [tese]. São Paulo: Pontifícia Universidade Católica de São Paulo; 2006.

21. Brasil. Decreto n0 3.321, de 30 de dezembro de 1999. Promulga o Protocolo Adicional à Convenção Americana sobre Direitos Humanos em Matéria de Direitos Econômicos, Sociais e Culturais "Protocolo de São Salvador", concluído em 17 de novembro de 1988, em São Salvador, El Salvador. Diário Oficial da União 31 dez. 1999.

22. United Nations. General Comment 12. The right to food. General Comment by the United Nations Committee on Economic Social and Cultural Rights, E/C.12/1999/5. Geneve: UN; 1999 [Internet]. acesso em 03 jan. 2013]. Disponível em: http://www.unhchr.ch/tbs/doc.nsf/0/3d02758c707031d5 $8025677 f 003 b 73 b 9$

23. Brasil. Emenda Constitucional no 64, de 4 de fevereiro de 2010. Altera o art. $6^{\circ}$ da Constituição Federal, para introduzir a alimentação como direito social. Diário Oficial da União 04 fev. 2010.

24. Brasil. Ministério da Saúde. Política nacional de alimentação e nutrição. 2. ed. rev. Brasília: Ministério da Saúde; 2007. 48 p.

25. Brasil. Portaria no 2.715, de 17 de novembro de 2011. Atualiza a Política Nacional de Alimentação e Nutrição. Diário Oficial da União, 18 nov. 2011; (22):89

26. Brasil. Lei no 11.346, de 15 de setembro de 2006. Cria o Sistema Nacional de Segurança Alimentar e Nutricional - SISAN com vistas em assegurar o direito humano à alimentação adequada e dá outras providências. Diário Oficial da União, 18 set. 2006.

27. Brasil. Decreto n ${ }^{\circ}$ 7.272, de 25 de agosto de 2010. Regulamenta a Lei no 11.346, de 15 de setembro de 2006, que cria o Sistema Nacional de Segurança Alimentar e Nutricional - SISAN com vistas a assegurar o direito humano à alimentação adequada, institui a Política Nacional de Segurança Alimentar e Nutricional - PNSAN, estabelece os parâmetros para a elaboração do Plano Nacional de Segurança Alimentar e Nutricional, e dá outras providências. Diário Oficial da União 26 ago. 2010.

28. Piovesan F. Direitos humanos e direito constitucional internacional. São Paulo: Saraiva; 2009.

29. Bobbio N. Teoria do ordenamento jurídico. 10ª ed. São Paulo: Pólis; UnB; 1997.

30. Assembléia Geral das Nações Unidas. Declaração Universal Dos Direitos Humanos. 10 dez. 1948. [Internet]. [acesso em: 02 jan. 2013]. Disponível em: http://portal.mj.gov.br/sedh/ct/legis_intern/ ddh_bib_inter_universal.htm

31. Brasil. Decreto n0 592, de 6 de julho de 1992. Atos Internacionais . Pacto Internacional sobre Direitos Civis e Políticos. Promulgação [Internet]. [acesso em 03 jan. 2013. Disponivel em: http://www. planalto.gov.br/ccivil_03/decreto/1990-1994/D0592.htm

32. Bontempo AG. Direitos sociais em juízo: mecanismos de aferição de resultado e controle do retrocesso social. Direitos sociais em juízo: mecanismos de aferição de resultado e controle do retrocesso social [tese]. São Paulo: Pontifícia Universidade Católica de São Paulo, São Paulo; 2009. 
33. Barroso LR. O direito constitucional e a efetividade de suas normas. $8^{a}$ ed. Belo Horizonte: Del Rey; 2006.

34. Brasil. Constituição 1988. Ato das Disposições Constitucionais Transitórias. Atos Decorrentes do disposto no $\int 3^{\circ}$ do art. $5^{\circ}$ [Internet]. [acesso em 04 jan. 2014]. Disponívele em: http://www.planalto. gov.br/ccivil_03/constituicao/constituicao.htm

35. Brasil. Lei no 8.069, de 13 de julho de 1990. Dispõe sobre o Estatuto da Criança e do Adolescente e dá outras providências. Diário Oficial da União 16 jul. 1990.

36. Brasil. Lei no 8.078, de 11 de setembro de 1990. Dispõe sobre a proteção do consumidor e dá outras providências. Diário Oficial da União 12 set. 1990.

37. Malfatti AD. O princípio da informação no Código de Defesa do Consumidor [dissertação]. São Paulo: Pontifícia Universidade Católica de São Paulo; 2001.

38. Concepção contemporânea de direitos humanos: desafios e perspectivas. In: Rocha JCC, Henriques Filho THP, Cazetta U. Direitos humanos: desafios humanitários contemporâneos: 10 anos do estatuto dos refugiados (lei n. 9.474 de 22 de julho de 1997). Belo Horizonte: Del Rey; 2008.

39. Costa SA. Desenvolvimento ético sob a égide da responsabilidade socioambiental [dissertação]. São Paulo: Pontifícia Universidade Católica de São Paulo; 2008.

40. Pfeiffer MCM. Direito à informação e ao consumo sustentável [tese]. São Paulo: Universidade de São Paulo; 2011.

41. Marques CL. Contratos no código de defesa do consumidor: o novo regime das relações contratuais. $5^{a}$ ed. São Paulo: RT; 1992.

42. Direitos básicos: comentários ao artigo 6º do CDC. In: Sodré MG, Meira F, Caldeira P, organizadores. Comentários ao código de defesa do consumidor. São Paulo: Verbatin; 2009. p. 63.

43. Benjamim AH. Contratos no código de defesa do consumidor: o novo regime das relações contratuais. $5^{a}$ ed. São Paulo: RT; 2005.

44. Andrighi FN. O Código de defesa do consumidor pela jurisprudência do Superior Tribunal de Justiça. In: Morato AC, Neri PT. 20 anos do código de defesa do consumidor. São Paulo: Atlas; 2010.

45. Pfeiffer RAC. Defesa da concorrência e bem-estar do consumidor [tese]. São Paulo: Universidade de São Paulo; 2010.

46. Benjamin AHV, Marques CL, Bessa LR. Manual de direito do consumidor. 2. ed. rev., atual. e ampl. São Paulo: RT; 2009.

47. Brasil. Decreto no 2.181, de 20 de março de 1997. Dispõe sobre a organização do Sistema Nacional de Defesa do Consumidor - SNDC, estabelece as normas gerais de aplicação das sanções administrativas previstas na Lei no 8.078, de 11 de setembro de 1990, revoga o Decreto No 861, de 9 julho de 1993 , e dá outras providências. Diário Oficial da União 21 mar. 1997.

48. Benjamim AHV. Fato do produto e do serviço. In: Benjamim AHV., Marques CL, Bessa LR. Manual de direito do consumidor. São Paulo: Revista dos Tribunais; 2007. 
49. Teixeira LC. A bioética e os alimentos transgênicos no âmbito do código de defesa do consumidor [dissertação]. São Paulo: Pontifícia Universidade Católica de São Paulo; 2007.

50. São Paulo. Tribunal de Justiça $6^{a}$ Câmara de Direito Privado, 0016491-54.2001.8.26.0000, rel. José Joaquim dos Santos, j. 04/03/2010, DJ 30/03/10.

51. São Paulo. Tribunal Regional Federal $3^{a}$ Região, $3^{a}$ Turma, rel. Rubens Calixto, 200461000316034, j. 30/06/11, DJ 15/07/11.

52. Rio Grande do Sul. Tribunal de Justiça 6 Câmara Cível, rel. Des. Artur Arnildo Ludwig, Ap. Civ. $n^{\circ} 70046666319 / 2011$, DJ 21/09/12.

53. Derr LE. When food is poison: the history, consequences, and limitations of the food allergen labeling and consumer protection act of 2004. Food and Drug Law Journal 2006; 61(1):65-165.

54. Brasil. Agência Nacional de Vigilância Sanitária. Consultas públicas em andamento [Internet]. [acesso em 18 jun. 2014. Disponível em: http://portal.anvisa.gov.br/wps/content/anvisa+portal/anvisa/ regulacao + sanitaria/assuntos + de + interesse/consultas + publicas/assuntos + de + interesse/consultas + publicas+em+andamento/2014060529

55. Brasil. Agência Nacional de Vigilância Sanitária. Consulta Pública no 29/2014 - Rotulagem de alergênicos em alimentos [Internet]. [aacesso em 18 jun. 2014]. Disponível em: http://formsus.datasus. gov.br/site/resultado.php?id_aplicacao $=16061$

Recebido: 07/4/2014

Revisado: $27 / 4 / 2014$

Aprovado: 20/6/2014 